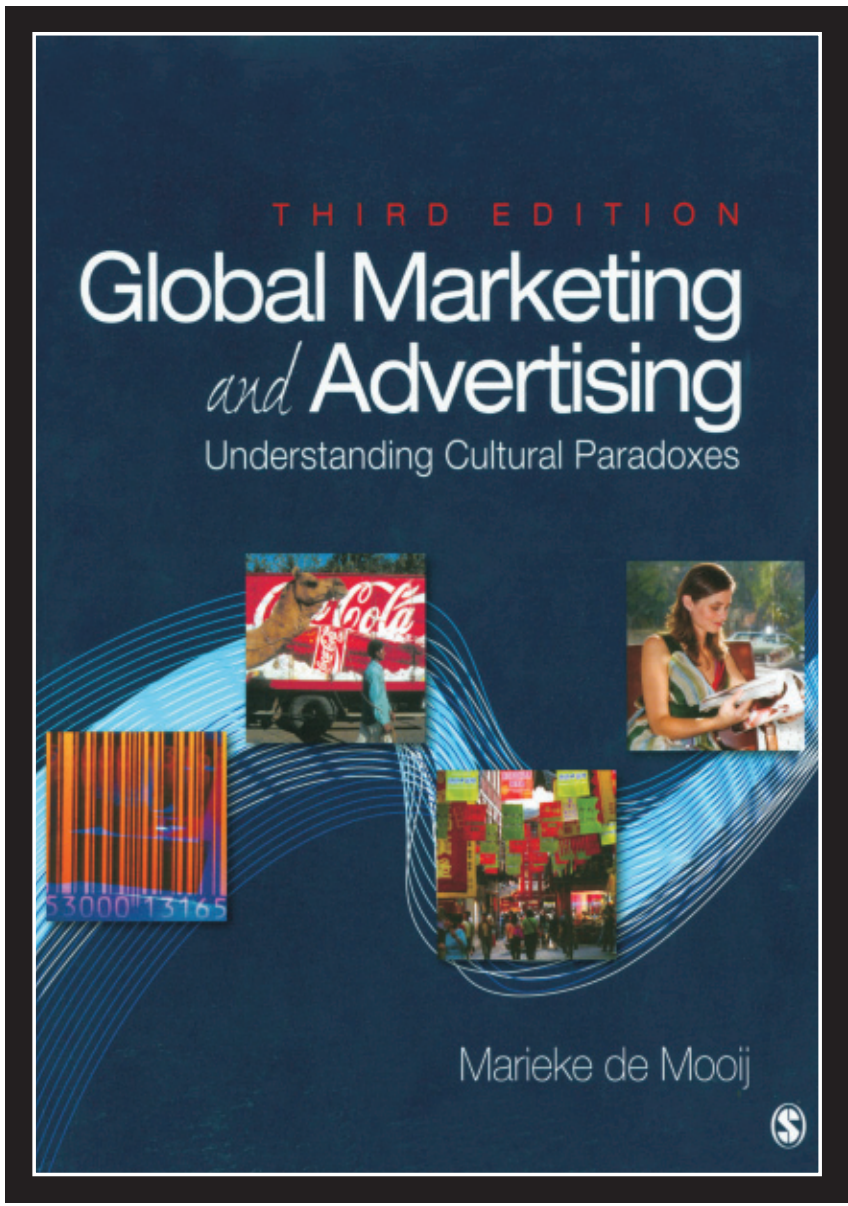

Global marketing and advertising: understanding cultural paradoxes, de Marieke de Mooij, $3^{\text {rd }}$ ed. Thousand Oaks, CA. Sage Publications, 2010, 322p. 


\section{Os mitos do marketing global \\ e da globalização}

Global marketing and globalization miths

Renato Rodrigues Martins *

O consumidor - esse ser que deseja ser globalizado - não é o mesmo ao redor do mundo, e as diferenças em seu comportamento aumentam entre os países com maior riqueza. Com a ampliação das posses, os valores culturais também são alterados e refletem nos hábitos de consumo. No que diz respeito às características culturais, o comportamento do consumidor está divergindo em vez de convergir. Ai começam os paradoxos.

Certamente, a principal tarefa do marketing no terceiro milênio é comunicacional e, neste quesito, os valores culturais são de extrema importância para a análise do cenário internacional. As organizações brasileiras estão se internacionalizando - ainda que tardiamente - e as informações deste livro são relevantes para a compreensão das peculiaridades culturais dos mercados internacionais.

Como o título sugere, a obra trata das influências culturais nas áreas da comunicação, da propaganda e, de maneira mais ampla, do marketing. Em sua terceira edição, revisada, ampliada (ela é original de 1998) e com novos casos e exemplos internacionais, o leitor poderá encontrar valiosos recursos, como auxílio instrucional e audiovisual, questões e pontos para discussões, atividades, links e apresentações em slides.

Nesta versão, a autora inclui novos tópicos, informações e resultados de estudos recentes que ajudam os leitores a entender e aplicar os conceitos de marketing transcultural para a gestão internacional da marca global e da comunicação de marketing. Entre os novos temas, destaque para

* Professor de graduação e pós-graduação da Universidade Estadual de Londrina (UEL). Pesquisador e líder do grupo de pesquisa em Comunicação Mercadológica Transcultural, cadastrado no CNPq. E-mail: profrenatomartins@gmail.com 
relações públicas globais, cultura e meios de comunicação, cultura e comunicação visual e cultura e internet, além de ampla abordagem sobre o comportamento do consumidor.

Ela auxilia profissionais e organizações a analisar mercados internacionais em outras culturas. Com profundidade, investiga a influência da cultura na comunicação em diferentes países, com destaque para exemplos vindos da Europa, o que é raro, pois foge dos modelos americanos. Mas peca, por não apresentar estudos relativos às características culturais latino-americanas, por exemplo. Carecem exemplos de países com economias emergentes, como a China, o Brasil e a Índia.

Global marketing and advertising pode ser utilizado como uma ferramenta por estudantes, profissionais de comunicação e de marketing e empresários internacionais para a compreensão dos paradoxos culturais da globalização, as estratégias de construção de marca globais, os paradoxais modelos de classificação da cultura e as consequências -e interferências - da cultura na comunicação mercadológica.

A obra explicita como a cultura afeta os assuntos estratégicos de uma organização, como a sua missão, o posicionamento de marca e a comunicação estratégica mercadológica. Demonstra a centralidade do paradoxo dos valores transculturais na comunicação mercadológica, e, infere ainda, várias alusões a campanhas e peças de propaganda - clássicas e modernas - de diferentes partes do mundo. O livro traz uma competente visão sobre os diversos conceitos de culturas.

De Mooij, como fiel discípula do antropólogo holandês Geert Hofstede, não poderia deixar de discutir os modelos culturais - as dimensões culturais de Hofstede - que, aceitos internacionalmente, elucidam as interações entre as culturas das organizações e as culturas nacionais. $\mathrm{O}$ modelo é considerado um subsídio com relação à classificação da cultura (outro paradoxo), pois a pesquisa utilizou amostra de mais de $100 \mathrm{mil}$ trabalhadores em de 50 países.

Hofstede identificou características que diferenciam os comportamentos profissionais, variando de acordo com a cultura. São dimensões que permitem classificar as culturas em: a) distância do poder 
(modo de encarar a desigualdade), b) aversão à incerteza (grau de tolerância ao desconhecido), c) grau de machismo e feminismo (diferenças entre o papel social masculino e feminino), d) caráter coletivista e individualista (grau de integração do indivíduo), e e) concepção temporal (orientação de curto e longo prazo).

Global marketing and advertising foi desenvolvido em uma base de conhecimentos sobre as semelhanças e as diferenças culturais, bem como criou uma estrutura funcional para aplicar esses conhecimentos em comunicação mercadológica e na gestão da marca global. A obra oferece uma combinação entre a teoria e a prática, analisando estratégias globais, modelos de classificação da cultura e as influências culturais para a comunicação de marketing e publicidade.

A autora afirma que, como produtores e consumidores do mercado global, as pessoas estão constantemente sujeitas a programas de marketing e comunicação persuasiva que influenciam suas percepções e comportamentos aquisitivos. $\mathrm{O}$ estudo busca criar uma consciência dos paradoxos da linguagem publicitária e da comunicação de marketing enfrentados pelas organizações que desejam ter suas mensagens recebidas e aceitas globalmente.

O leitor (profissional, educador ou estudante) poderá, com esse material, desenvolver uma compreensão das relações entre a cultura e o comportamento do consumidor, no que diz respeito à construção da marca e a comunicação do marketing, tanto a institucional quanto a persuasiva, da publicidade. É um estudo composto de aplicativos do mundo dos negócios com base nas teorias administrativas e mercadológicas modernas.

De uma forma bastante prática a acessível, Marieke de Mooij traz em sua obra um sumário rápido e outro com maior profundidade de detalhes, que se segue:

O capítulo 1, Os paradoxos da comunicação mercadológica global, apresenta os conceitos de paradoxo de valor, os paradoxos da globalização e as teorias do marketing global. As inquietantes abordagens do dilema "global-local" são discutidas à exaustão e também são tratados alguns mitos do marketing global. As questões das comunidades globais 
e as convergências do comportamento dos consumidores são exemplos abordados neste capítulo, passando pela estandardização e adaptação dos mercados globais.

O segundo capítulo, Gestão global de marcas, discorre sobre o conceito de marca, de modelos de gestão de marca (o chamado branding) e os diferentes aspectos culturais de uma marca globalizada, como características de uma marca de sucesso, de percepção de consumo de marcas globais e o papel da comunicação na construção de uma marca global. O capítulo é encerrado com a discussão da marca como uma rede associativa na mente dos consumidores.

No capítulo 3, Cultura e valor, a autora apresenta o conceito de marca e de cultura, nos mais diferentes aspectos da cultura, como as manifestações culturais na linguagem oral e corporal, nos signos, nos sinais e nos símbolos, no imaginário coletivo, nos estereótipos e na música. Também apresenta uma extensa comparação de características culturais.

O capítulo 4, Dimensões da cultura, descreve diferentes classificações de dimensões culturais, os conceitos de tempo e de espaço e ainda o de alto e baixo contexto na comunicação. Discute a ideia de que o conceito de tempo pode ser linear ou circular, monocrônico ou policrônico. São exploradas com detalhamento, neste capítulo, as dimensões culturais de Hofstede, que serão apresentadas em toda a extensão da obra.

No capítulo 5, Cultura e comportamento do consumidor, a autora apresenta uma visão geral das influências da cultura em várias teorias do comportamento do consumidor. Os modernos conceitos de cultura e suas influências no comportamento do consumidor são abordados nesse capítulo, com destaque para a motivação ao consumo, identidade, necessidade, personalidade, estilo de vida e ainda os atributos do consumo, os processos sociais - e grupais - os processos mentais e domínios do comportamento do consumidor.

No sexto capítulo, Pesquisa e aplicação de valores culturais, o tema central é a investigação e suas aplicações na gestão da comunicação transcultural. O capítulo lida também com a comparação das diferenças do Modelo Hofstede, que oferece valores específicos para a comunicação 
de marketing em cada cultura. Apresenta ao leitor mapas para estruturar os valores de investigação e de compreensão de grupos, para comparar os valores culturais e os valores comerciais relativos ao estilo de vida do consumidor.

O capítulo 7, Cultura e comunicação, é, sem dúvida, o de maior importância aos comunicadores, pois aborda densamente a comunicação pela ótica da cultura. Trata da comunicação interpessoal em cada cultura. Discute as influências culturais nas linguagens e nos meios eletrônicos e impressos de massa. As formas como as pessoas se comunicam são relacionadas com a cultura e influenciadas por seus valores. O capítulo aborda também a interface da cultura e das relações públicas, as influências culturais no design, no logotipo, no produto e nas suas embalagens.

No oitavo capítulo, Cultura e os meios de comunicação, são discutidos temas como mídia e cultura, com destaque para como os veículos de comunicação são influenciados. Aborda as mídias tradicionais como televisão, rádio, jornais e revistas e as novas tecnologias eletrônicas. Várias mídias da internet são discutidas em profundidade, como o e-commerce, as redes sociais e os blogs e suas interferências culturais. Os virais, os vídeos publicitários online e a publicidade móvel na internet também são cobertos neste capítulo.

O capítulo 9, Cultura e os apelos publicitários, discorre sobre os paradoxos dos apelos da propaganda e explica como esses recursos têm reflexos na cultura. Apresenta o paradoxo de dependência e liberdade, de sucesso e de inovação. Exemplifica os apelos da propaganda nas dimensões culturais de Hofstede. Questiona se os conceitos de grandes campanhas publicitárias - como de humor, por exemplo - podem ser exportados e compreendidos em outras culturas.

No capítulo 10, Cultura e estilo de execução, são apresentados, com exemplos, sete modelos básicos de formatos de propagandas mundiais e o grau com que eles se relacionam culturalmente. Também são discutidos temas como anúncios, drama, entretenimento e modelos básicos de relacionamento. 
O capítulo 11, Do paradoxo de valor à estratégia, único escrito com a colaboração da Ph.D. Arne Mass, lida quase que exclusivamente com questões práticas de estratégias empresariais. Apresenta a ideia de que a missão e a identidade corporativa, assim como os produtos e os mercados são influenciados pela cultura. Discute ainda a ideia de que o posicionamento de marca, com identidade e imagem fortes, é mais difícil de ser consolidada em culturas diferentes daquelas onde foram concebidas. Para finalizar, o capítulo faz uma revisão de estratégias comunicacionais mercadológicas em diferentes fases de desenvolvimentos de mercados.

Ao final, o livro apresenta dois apêndices que podem ser utilizados para uma substancial análise dos mercados internacionais. O primeiro traz o GNI/Capita 2007 em dólares americanos de 66 países. É uma espécie de PIB (Produto Interno Bruto) comparado com a pontuação da classificação das dimensões culturais de Hofstede. O segundo apêndice apresenta, de forma organizada, uma base de dados (database) que foi utilizada para a pesquisa deste livro.

A autora, Ph.D. Marieke de Mooij, é professora e pesquisadora na Holanda, onde trabalha como consultora em comunicação transcultural. É professora visitante de várias universidades europeias como a de Navarra, na Espanha, a de Vaasa, na Finlândia, e na Universidade Europeia de Viadrina, na Alemanha. Em sua terra natal, ministra aulas nos cursos de graduação e de pós-graduação na Universidade de Groningen (Academie voor Management). É autora de várias publicações que tratam da influência da cultura no marketing e na propaganda. Seu mais recente livro, aqui resenhado, é utilizado por profissionais e universidades em todo o mundo. É, sem dúvida, o livro mais especializado sobre cultura e comportamento do consumidor. 